\title{
Adiponectin as a Biomarker of the Metabolic Syndrome
}

\author{
Miwa Ryo, MD; Tadashi Nakamura, MD; Shinji Kihara, MD; Masahiro Kumada, MD; \\ Satomi Shibazaki, MD*; Mihoko Takahashi, PhD*; Masaki Nagai, MD*; \\ Yuji Matsuzawa, MD**; Tohru Funahashi, MD
}

\begin{abstract}
Background The metabolic syndrome, a cluster of abdominal obesity, dyslipidemia, hypertension and hyperglycemia, is a common basis for atherosclerotic vascular diseases in industrial countries exposed to overnutrition. Adiponectin is an adipose-derived plasma protein with anti-atherogenic and insulin-sensitizing activities.

Methods and Results A total of 661 Japanese adults (479 men, 53 \pm 10 years; 182 women 56 \pm 10 years) were enrolled. Plasma adiponectin concentrations correlated negatively with waist circumference, visceral fat area, serum triglyceride concentration, fasting plasma glucose, fasting plasma insulin, and systolic and diastolic blood pressure in both sexes. A positive correlation was found between plasma adiponectin and high-density lipoprotein cholesterol concentrations in both sexes. The mean number of components of the metabolic syndrome increased as the plasma adiponectin concentration decreased: $2.57 \pm 1.34$ for men and $2.00 \pm 1.51$ for women with adiponectin concentrations $<4.0 \mu \mathrm{g} / \mathrm{ml}$. In all, $52.3 \%$ of men and $37.5 \%$ of women with adiponectin concentrations $<4.0 \mu \mathrm{g} / \mathrm{ml}$ fulfilled the criteria for metabolic syndrome.

Conclusion Hypoadiponectinemia is closely associated with the clinical phenotype of the metabolic syndrome and measuring the plasma concentration of adiponectin may be useful for management of the metabolic syndrome. (Circ J 2004; 68: 975-981)
\end{abstract}

Key Words: Adipocytokine; Adiponectin; Hypoadiponectinemia; Metabolic syndrome; Visceral fat

$A^{n}$

$\mathrm{n}$ elevated plasma concentration of low-density lipoprotein (LDL)-cholesterol is one of the major risk factors for the development of coronary artery disease (CAD). Clinical trials have demonstrated that LDL-lowering therapy can reduce major coronary events and coronary mortality! A secondary target for the prevention of CAD beyond cholesterol-lowering therapy is management of the metabolic syndrome, which comprises a cluster of cardiovascular risk factors, including abdominal obesity, dyslipidemia, glucose intolerance and hypertension. Although genetic factors may be involved, it has been generally accepted that accumulation of excess body fat, particularly abdominal obesity or intra-abdominal visceral obesity caused by overnutrition and physical inactivity, promotes the development of the metabolic syndrome ${ }^{2-8}$

Recent research has demonstrated that adipose tissue produces and secretes various bioactive substances, conceptualized as adipocytokines, and their dysregulation in abdominal or visceral obesity may participate in the development of the metabolic syndrome9-11 For example, overproduction of plasminogen activator inhibitor type 1 in excess visceral fat inhibits the fibrinolytic system and consequently may lead to thrombotic vascular disorders 11 Adiponectin is an adipose-specific plasma protein, which we identified in the human adipose cDNA project! ${ }^{2}$

(Received June 14, 2004; revised manuscript received August 9, 2004; accepted August 23, 2004)

Department of Internal Medicine and Molecular Science, Graduate School of Medicine, Osaka University, Suita, Osaka, *Department of Public Health, Saitama Medical School, Saitama and **Sumitomo Hospital, Osaka, Japan

Mailing address: Tohru Funahashi, MD, PhD, Department of Internal Medicine and Molecular Science, Graduate School of Medicine, Osaka University, 2-2 Yamadaoka, Suita, Osaka 565-0871, Japan.

E-mail: tohru@imed2.med.osaka-u.ac.jp
Adiponectin suppresses almost all processes involved in atherosclerotic vascular change, including the expression of adhesion molecules in vascular endothelial cells, ${ }^{13,14}$ proliferation of vascular smooth muscle cells $1^{15}$ and formation of foam cells in vitro ${ }^{16}$ and it exhibits anti-atherosclerotic activity in vivo ${ }^{17}$ However, low plasma adiponectin concentrations are found in obese subjects ${ }^{18}$ We and others have also demonstrated that adiponectin has insulin-sensitizing activity, and that high plasma adiponectin is a negative risk factor for type 2 diabetes in diabetes-prone people! ${ }^{1-21}$ Recent studies have shown that adiponectin is related to endothelium-dependent vasodilatation and its plasma concentrations are low in subjects with essential hypertension?22 These clinical and experimental data suggest that adiponectin may play a significant role in the development of the metabolic syndrome.

The significance of plasma adiponectin measurement in subjects with the metabolic syndrome has not been well studied. In the present study, we measured it in a large Japanese population and investigated the relationship between plasma adiponectin concentration and the metabolic syndrome.

\section{Methods}

\section{Subjects}

The study group comprised 661 Japanese adult subjects [mean age $\pm \mathrm{SD}, 54 \pm 10$ years, range: $20-78$ years; 479 men (53 \pm 10 years), 182 women ( $56 \pm 10$ years)]. To investigate the prevalence of the metabolic syndrome and the range of plasma adiponectin concentrations in the general Japanese population, 577 cases [ 438 men ( $54 \pm 9$ years), 139 women (55 \pm 8 years)], who underwent health examination in the institutions that participated in the Japanese Visceral Fat Syndrome (J-VFS) Study Committee of the Ministry of 
A

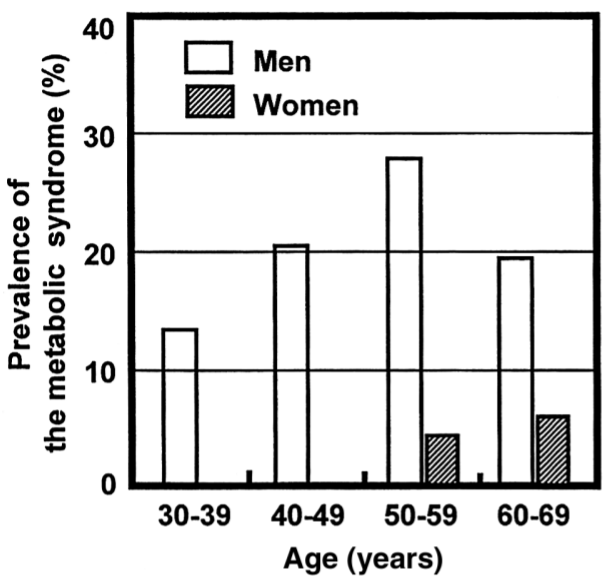

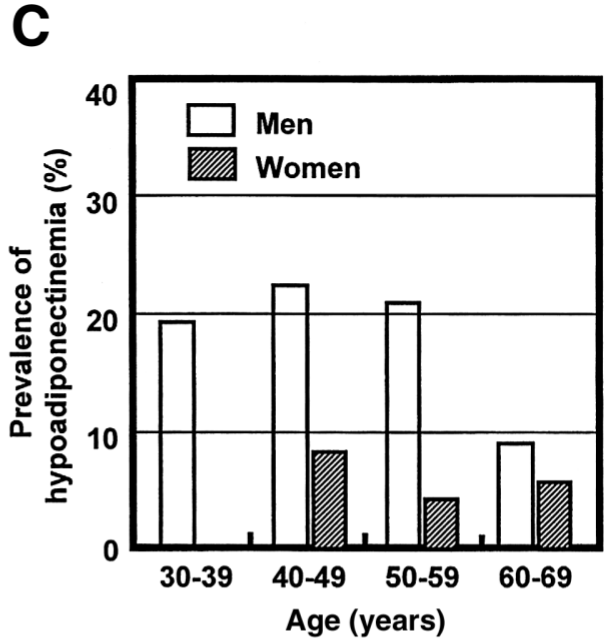

B

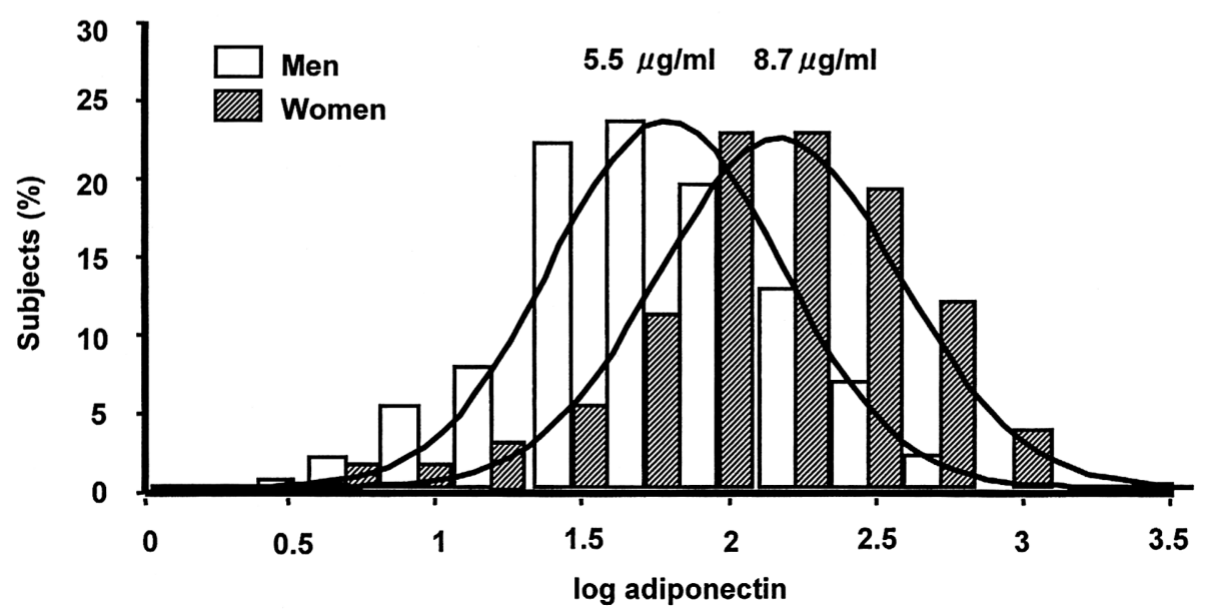

Fig 1. (A) Age-specific prevalence of the metabolic syndrome. (B) Percentages of subjects according to log adiponectin concentrations. Logarithmic transformation of plasma adiponectin concentrations was performed as needed to improve normality. (C) Age-specific prevalence of hypoadiponectinemia. Men $(n=438)$, women $(n=139)$.

Health and Welfare of Japan, and subjects who visited Osaka University Hospital for health check because of mild

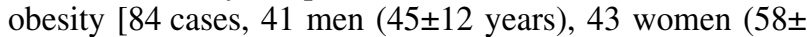
13 years)] were enrolled in the study. Informed consent was obtained from all subjects following the approval of the ethics committee of Osaka University. Among 661 subjects, $41(6.2 \%), 49(7.4 \%)$ and $34(5.1 \%)$ were being treated with an anti-hypertensive, anti-hyperlipidemic or anti-diabetic regimen, respectively. Therefore, not all the subjects were clinically normal, but were almost representative of the general Japanese population. Diabetic subjects treated with insulin were not included in this study. We and others have reported that thiazolidinediones increase plasma adiponectin concentrations dramatically, so none of the subjects in our study group were receiving thiazolidinediones.

\section{Anthropometry and Abdominal Fat Distribution}

Anthropometric measurements (height, weight and waist circumference) were performed in a standing position. Body mass index (BMI) was calculated as weight divided by the square of height in meters. Waist circumference (WC) at the umbilical level was measured in the late exhalation phase while standing, as reported previously?3 Blood pressure was measured in the sitting position. A computed tomography (CT) scan was performed in all subjects in the routine supine position. The intra-abdominal visceral fat area (VFA) and subcutaneous fat area (SFA) were measured from CT cross-sectional scans at the level of the umbilicus, as reported previously ? $^{4}$

\section{Laboratory Measurements}

Blood was withdrawn after an overnight fast and the plasma concentrations of adiponectin were measured by a sandwich enzyme-linked immunosorbent assay (ELISA) system (adiponectin ELISA kit, Otsuka Pharmaceutical Co), as reported previously ${ }^{18}$ Plasma glucose and serum insulin concentrations at $0,30,60$, and 120 min after $75-\mathrm{g}$ oral glucose were determined by the glucose oxidase method and double-antibody radioimmunoassay, respectively. The sums of the glucose and insulin concentrations during the oral glucose tolerance test (OGTT) were calculated as $\sum$ glucose and $\sum$ insulin. Serum total cholesterol and triglyceride concentrations were determined by enzymatic methods. High-density lipoprotein (HDL) cholesterol was also measured by an enzymatic method after heparin and calcium precipitation. 
Table 1 Clinical Characteristics of the Study Subjects

\begin{tabular}{lcc}
\hline \hline & Men $(n=479)$ & Women $(n=182)$ \\
\hline Age, years & $53.1 \pm 9.5$ & $55.7 \pm 9.5$ \\
BMI, $\mathrm{kg} / \mathrm{m}^{2}$ & $24.0 \pm 3.5$ & $24.2 \pm 4.1$ \\
WC, cm & $86.3 \pm 8.9$ & $82.3 \pm 11.6$ \\
Visceral fat area, $\mathrm{cm}^{2}$ & $105.7 \pm 52.8$ & $77.4 \pm 45.1$ \\
Subcutaneous fat area, $\mathrm{cm}^{2}$ & $123.1 \pm 70.2$ & $184.6 \pm 90.7$ \\
Adiponectin, $\mu \mathrm{g} / \mathrm{ml}(\mathrm{min}, \mathrm{max})$ & $5.4(0.8,15.2)$ & $8.2(0.3,20.9)$ \\
Category $1<4.0, n(\%)$ & $109(22.8)$ & $16(8.8)$ \\
Category 2 $\geq 4.0,<5.5, n(\%)$ & $137(28.6)$ & $18(9.9)$ \\
Category 3 $\geq 5.5,<7.0, n(\%)$ & $114(23.8)$ & $29(15.9)$ \\
Category 4 $\geq 7.0, n(\%)$ & $119(24.8)$ & $119(65.4)$ \\
Dyslipidemia, $n(\%)$ & $255(53.2)$ & $60(33.0)$ \\
Total cholesterol, $\mathrm{mg} / \mathrm{dl}$ & $198.8 \pm 32.5$ & $209.2 \pm 31.0$ \\
Triglyceride, $\mathrm{mg} / \mathrm{dl}$ & $144.9 \pm 99.8$ & $102.3 \pm 57.4$ \\
HDL cholesterol, $\mathrm{mg} / \mathrm{dl}$ & $50.8 \pm 14.5$ & $64.0 \pm 17.3$ \\
Hypertension, $n(\%)$ & $178(37.2)$ & $70(38.7)$ \\
Systolic blood pressure, $\mathrm{mmHg}$ & $123.8 \pm 17.2$ & $121.6 \pm 21.5$ \\
Diastolic blood pressure, $\mathrm{mmHg}$ & $73.8 \pm 12.3$ & $70.9 \pm 14.0$ \\
High fasting glucose, $n(\%)$ & $87(18.2)$ & $29(15.9)$ \\
Fasting plasma glucose, $\mathrm{mg} / \mathrm{dl}$ & $99.9 \pm 22.3$ & $97.1 \pm 21.8$ \\
\hline
\end{tabular}

BMI, body mass index; WC, waist circumference; HDL, high-density lipoprotein. Continuous variables, results are presented as mean $\pm S D$ or median (minimum, maximum).

\section{Definition of the Metabolic Syndrome}

There is not a current definition of the metabolic syndrome in Japan. In the present study, we tentatively defined it by modifying the criteria of the National Cholesterol Education Program's Adult Treatment Panel III report (NECPATP) $; 25$ that is, the presence of at least 3 of the following abnormalities: (1) abdominal obesity: $\mathrm{WC} \geq 85 \mathrm{~cm}$ in men or $\geq 90 \mathrm{~cm}$ in women according to the guidelines for diagnosis of 'Obesity Disease' in Japan;26 (2) hypertriglyceridemia: a serum triglyceride concentration $\geq 150 \mathrm{mg} / \mathrm{dl}(1.69 \mathrm{mmol} / \mathrm{L})$; (3) low HDL cholesterolemia: a serum HDL cholesterol concentration $<40 \mathrm{mg} / \mathrm{dl}(1.04 \mathrm{mmol} / \mathrm{L})$ according to the criteria of the Japan Atherosclerosis Society;27 (4) hypertension: systolic blood pressure $\geq 130 \mathrm{mmHg}$, diastolic blood pressure $\geq 85 \mathrm{mmHg}$ and/or having received antihypertensive medication; and (5) high fasting glucose: serum glucose concentration $\geq 110 \mathrm{mg} / \mathrm{dl}(6.1 \mathrm{mmol} / \mathrm{L})$ and/or having received antidiabetic medication (oral agents).

\section{Statistical Analysis}

For continuous variables, results were expressed as mean \pm SD or median (minimum, maximum). Pearson's correlation coefficient was used to establish the association between plasma adiponectin concentrations and clinical parameters of the metabolic syndrome. Data that did not demonstrate Gaussian distribution were logarithmically transformed. The subjects were divided into 2 groups according to their adiponectin concentration $(<4.0 \mu \mathrm{g} / \mathrm{ml}$ or $>4.0 \mu \mathrm{g} / \mathrm{ml}$ ). Category variables were represented by frequency counts, and comparisons between 2 groups were analyzed by the chi-square test. The interquartile cut-off points of plasma adiponectin concentration were 4.0, 5.5 , and $7.0 \mu \mathrm{g} / \mathrm{ml}$ : category $1,<4.0 \mu \mathrm{g} / \mathrm{ml}$; category 2 , $\geq 4.0 \mu \mathrm{g} / \mathrm{ml},<5.5 \mu \mathrm{g} / \mathrm{ml}$; category $3, \geq 5.5 \mu \mathrm{g} / \mathrm{ml},<7.0 \mu \mathrm{g} / \mathrm{ml}$; and category $4, \geq 7.0 \mu \mathrm{g} / \mathrm{ml}$ as described previously? 28 The comparison of the mean number of components of the metabolic syndrome in each adiponectin quartile was analyzed by Kruskal-Wallis test with a Scheffe's test. All statistical analyses were performed with StatView-J 5.0 (SAS Inc).
Table 2 Correlation Coefficients of the Relationships Between Plasma Adiponectin Concentration and Various Parameters of the Metabolic Syndrome

\begin{tabular}{lcc}
\hline \hline & Men $(n=479)$ & Women $(n=182)$ \\
\hline Age & $0.19 * * * *$ & 0.14 \\
BMI & $-0.36 * * * *$ & $-0.33 * * * *$ \\
WC & $-0.32 * * * *$ & $-0.33 * * * *$ \\
Visceral fat area & $-0.29 * * * *$ & $-0.24 * *$ \\
Subcutaneous fat area & $-0.27 * * * *$ & $-0.22 * *$ \\
Total cholesterol & $-0.10 *$ & 0.02 \\
Triglyceride & $-0.36 * * * *$ & $-0.29 * * * *$ \\
HDL cholesterol & $0.26 * * * *$ & $0.43 * * * *$ \\
Systolic blood pressure & $-0.13 * *$ & $-0.18 *$ \\
Diastolic blood pressure & $-0.20 * * * *$ & $-0.17 *$ \\
Fasting plasma glucose & $-0.22 * * * *$ & $-0.16 *$ \\
Fasting plasma insulin & $-0.18 * * * *$ & $-0.29 * * * *$ \\
Eplasma glucose & $-0.22 * * * *$ & $-0.24 * *$ \\
Eplasma insulin & $-0.14 * *$ & $-0.30 * * *$ \\
\hline
\end{tabular}

${ }^{*} p<0.05, * * p<0.01, * * * p<0.001, * * * * p<0.0001$, Pearson's correlation coefficients.

$B M I$, body mass index; WC, waist circumference; $H D L$, high-density lipoprotein; $\sum$ plasma glucose, sum of the glucose concentrations during the OGTT; Eplasma insulin, sum of the insulin concentrations during the OGTT.

\section{Results}

Prevalence of the Metabolic Syndrome and the Distribution of Plasma Adiponectin Concentration in the Japanese Population

Based on our criteria, $22.8 \%$ of men and $3.6 \%$ of women were diagnosed with the metabolic syndrome. In men, the prevalence increased from $13.3 \%$ among subjects aged $30-39$ years to $27.7 \%$ among those aged $50-59$ years, but decreased to $19.2 \%$ among men $60-69$ years (Fig 1A). The prevalence of the metabolic syndrome in women was $4.2 \%$ and $5.7 \%$ for subjects aged $50-59$ years and 60-69 years, respectively (Fig 1A). Therefore, the prevalence of the metabolic syndrome was highest in middle-aged men, and increased from the age of menopause in women.

Next, we determined the distribution of plasma adiponectin concentrations in this population and found that in both men and women the percentage of subjects was parametrically distributed against logarithmically transformed adiponectin concentrations (Fig 1B). The median concentration of plasma adiponectin was $6.1 \mu \mathrm{g} / \mathrm{ml}$ for the whole population sample. The distribution of the plasma adiponectin concentrations in men was lower than in women. The median concentrations of plasma adiponectin were $5.5 \mu \mathrm{g} / \mathrm{ml}$ in men and $8.7 \mu \mathrm{g} / \mathrm{ml}$ in women. We reported previously that subjects with a plasma adiponectin concentration less than $4.0 \mu \mathrm{g} / \mathrm{ml}$ had a 2 -fold increase in the prevalence of CAD? 8 In the present study the prevalence of hypoadiponectinemia less than $4.0 \mathrm{\mu g} / \mathrm{ml}$ was $18.7 \%$ in men and $5.0 \%$ in women. The cut-off point of $4.0 \mu \mathrm{g} / \mathrm{ml}$ corresponded with median -1.4 median absolute deviation of the total subjects. The prevalence of hypoadiponectinemia in men and women was similar to that of the metabolic syndrome (Fig 1C).

\section{Relationship Between Plasma Adiponectin Concentration and Each Component of the Metabolic Syndrome}

We investigated the relationship between plasma adiponectin concentration and each component of the metabolic syndrome. The clinical characteristics and variables of the subjects are shown in Table 1 . The correlation coefficient 

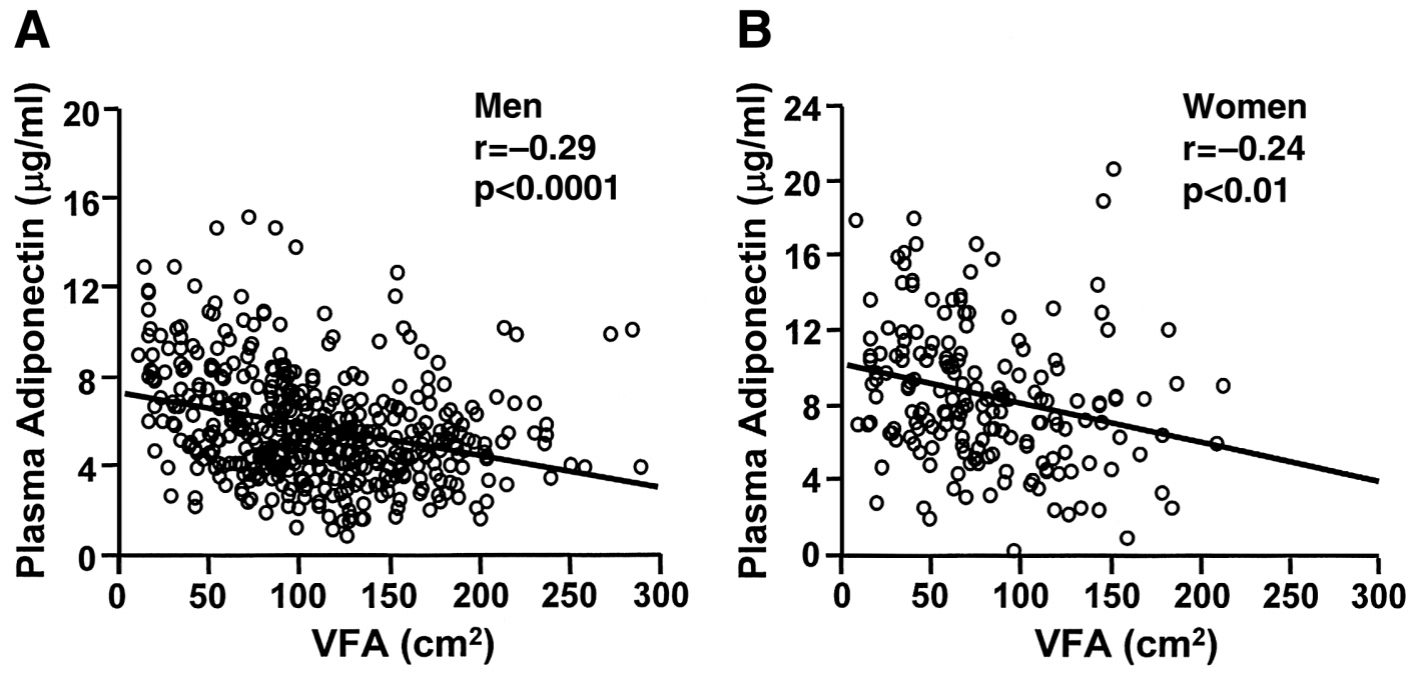

Fig 2. Correlation between visceral fat area (VFA) and plasma adiponectin concentration: men ( $=479)$, women $(\mathrm{n}=182)$.

A

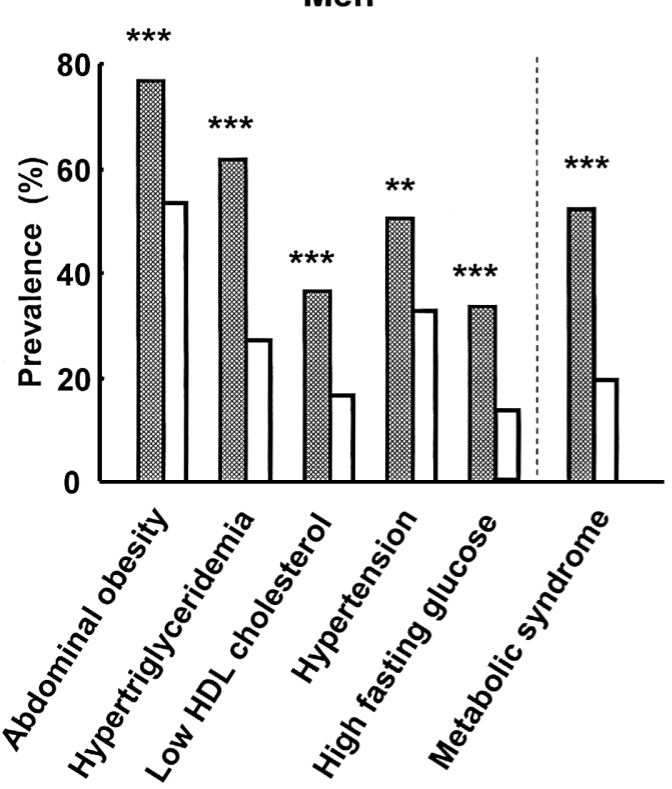

B

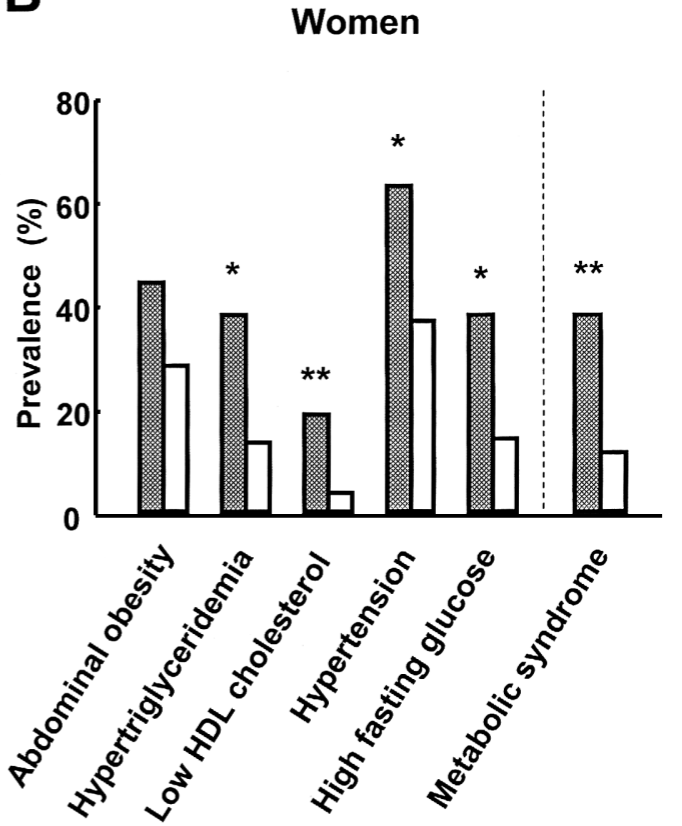

Adiponectin $<4.0 \mu \mathrm{g} / \mathrm{ml}$

Adiponectin $\geq 4.0 \mu \mathrm{g} / \mathrm{ml}$

Fig 3. Prevalence of risk factors of the metabolic syndrome: men $(n=479)$, women $(n=182) . * p<0.05$, **p<0.01, $* * * \mathrm{p}<0.001$, Adiponectin $<4.0 \mu \mathrm{g} / \mathrm{ml}$ vs adiponectin $\geq 4.0 \mu \mathrm{g} / \mathrm{ml}$ by chi-square test.

between plasma adiponectin and various parameters of the metabolic syndrome are shown in Table 2 . With regard to the anthropometric parameters, plasma adiponectin concentration correlated negatively with BMI, WC, VFA, and SFA in both men and women. The correlation efficiency between plasma adiponectin concentration and VFA was $r=-0.29(p<0.0001)$ in men and $r=-0.24(p<0.01)$ in women (Fig 2). Among the parameters related to the metabolic syndrome, plasma adiponectin concentration correlated negatively with total cholesterol, triglyceride, systolic BP, diastolic BP, fasting plasma glucose, fasting plasma insu- lin, Eplasma glucose, and $\sum$ plasma insulin, and positively with HDL cholesterol in men. In women, plasma adiponectin levels correlated negatively with triglyceride, systolic $\mathrm{BP}$, diastolic BP, fasting plasma glucose, fasting plasma insulin, Eplasma glucose, and Eplasma insulin, and positively with HDL cholesterol. No correlation was found between plasma adiponectin and total cholesterol in women. The presence of diabetes may affect the relationship between plasma adiponectin and $\sum$ plasma glucose or $\sum$ plasma insulin. However, similar results were obtained even when we excluded the diabetic subjects under medication (cor- 


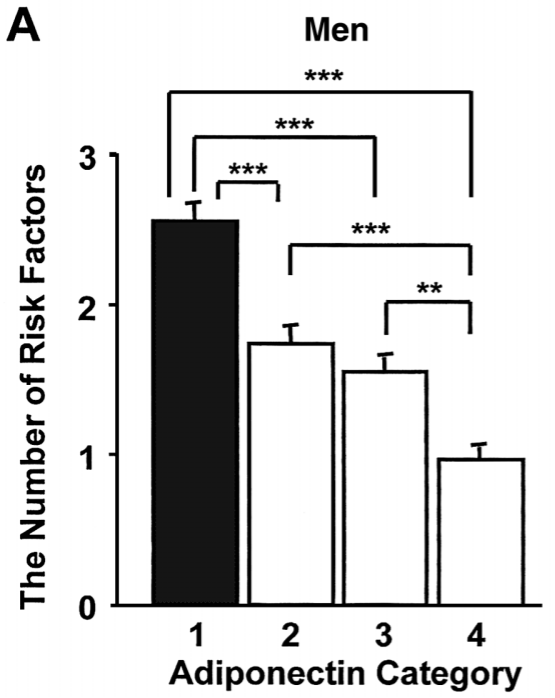

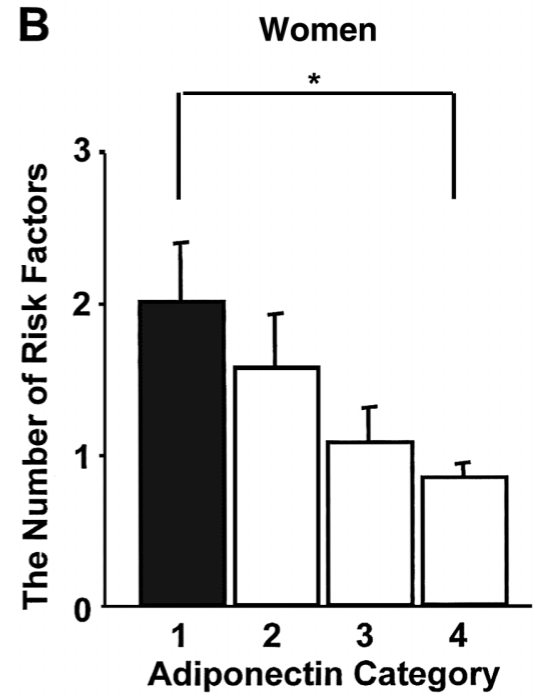

Fig 4. Mean number of components of the metabolic syndrome in each of the quartiles based on plasma adiponectin concentration: men $(n=479)$, women $(n=182)$. Risk factors: abdominal obesity, hypertriglyceridemia, low HDL cholesterol, hypertension, high fasting glucose. Data are mean \pm SEM. $* p<0.05$, $* * \mathrm{p}<0.01, * * * \mathrm{p}<0.001$ by Kruskal-Wallis test with a Scheffe's test. relation coefficients between plasma adiponectin and $\sum$ plasma glucose, $\sum$ plasma insulin were -0.26 and -0.15 in men, -0.29 and -0.31 in women, respectively.).

\section{Hypoadiponectinemia and the Prevalence of Components of the Metabolic Syndrome}

We divided the subjects into 2 groups according to their adiponectin concentrations using a cut-off point of $4.0 \mu \mathrm{g} / \mathrm{ml}$ and compared the prevalence of each component of the metabolic syndrome in the 2 groups (Fig 3 ). In men, subjects with an adiponectin concentration $<4.0 \mu \mathrm{g} / \mathrm{ml}$ showed a higher prevalence of abdominal obesity $(76.1 \%$ vs $52.7 \%$, $\mathrm{p}<0.001$ ), hypertriglyceridemia (60.6\% vs $27.0 \%, \mathrm{p}<0.001)$, low HDL cholesterol (35.8\% vs $16.8 \%, \mathrm{p}<0.001)$, hypertension $(50.5 \%$ vs $33.2 \%, \mathrm{p}<0.01)$ and high fasting glucose $(34.0 \%$ vs $13.5 \%, \mathrm{p}<0.001)$ than those with an adiponectin concentration $\geq 4.0 \mu \mathrm{g} / \mathrm{ml}$. In addition, the female subjects with an adiponectin concentration $<4.0 \mu \mathrm{g} / \mathrm{ml}$ showed a higher prevalence of hypertriglyceridemia $(37.5 \%$ vs $13.3 \%, \mathrm{p}<0.05)$, low HDL cholesterol (18.8\% vs 3.6\%, $\mathrm{p}<0.01)$, hypertension $(62.5 \%$ vs $36.4 \%, \mathrm{p}<0.05)$ and high fasting glucose $(37.5 \%$ vs $13.9 \%, \mathrm{p}<0.05)$ than those with an adiponectin concentration $\geq 4.0 \mu \mathrm{g} / \mathrm{ml}$. The prevalence of the metabolic syndrome was higher in subjects with an adiponectin concentration $<4.0 \mathrm{\mu g} / \mathrm{ml}$ than in those with a concentration $\geq 4.0 \mu \mathrm{g} / \mathrm{ml}$ in both men $(52.3 \%$ vs $19.6 \%$, $\mathrm{p}<0.001)$ and women $(37.5 \%$ vs $11.4 \%, \mathrm{p}<0.01)$.

We also categorized the subjects into 4 groups according to their plasma adiponectin concentration: category 1 , $<4.0 \mu \mathrm{g} / \mathrm{ml}$; category $2, \geq 4.0 \mu \mathrm{g} / \mathrm{ml},<5.5 \mu \mathrm{g} / \mathrm{ml}$; category 3 , $\geq 5.5 \mu \mathrm{g} / \mathrm{ml},<7.0 \mu \mathrm{g} / \mathrm{ml}$; and category $4, \geq 7.0 \mu \mathrm{g} / \mathrm{ml}$ as described previously 28 The percentages of subjects in the 4 categories were $22.8 \%, 28.6 \%, 23.8 \%$ and $24.8 \%$, respectively, in men and $8.8 \%, 9.9 \%, 15.9 \%$ and $65.4 \%$ in women (Table 1). The mean number of components of the metabolic syndrome in each adiponectin quartile increased with the decrease in the quartiles of plasma adiponectin concentration in men (category 1: 2.57 \pm 1.34 ; category 2: $1.76 \pm 1.16$; category $3: 1.54 \pm 1.25$; category $4: 0.97 \pm 1.02$ ) (Fig 4A). Comparable data were also obtained in women (category 1: $2.00 \pm 1.51$; category $2: 1.56 \pm 1.54$; category 3 :

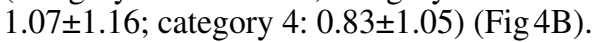

\section{Discussion}

The metabolic syndrome, representing a cluster of insulin resistance, glucose intolerance, hypertension and dyslipidemia, is a common basis for the development of atherogenic cardiovascular diseases, especially CAD, in industrial countries exposed to overnutrition:29,30 The molecular basis of the metabolic syndrome has not been elucidated. Adiponectin is an adipose-derived protein with multivalent functions including anti-atherogenic, insulinsensitizing, lipid-oxidation enhancing, and vasodilatory activities!2-17,19-22 Therefore, it is possible that decreased plasma concentrations of adiponectin plays a significant role in the development of the metabolic syndrome. In the present study, we demonstrated that the plasma concentration of adiponectin was significantly correlated with each component of the metabolic syndrome. Furthermore, multiplicity of the risk factors was higher in the category of subjects with lower plasma adiponectin concentration. Plasma adiponectin may therefore become a useful biomarker for the metabolic syndrome.

In the present study, we tentatively defined the metabolic syndrome using modified NCEP-ATPIII criteria ${ }^{25}$ appropriate for the Japanese population. The cut-off point of WC was $85 \mathrm{~cm}$ in men and $90 \mathrm{~cm}$ in women according to the criteria for abdominal obesity in the Japanese Society for the Study of Obesity, ${ }^{26}$ which corresponded to VFA of $100 \mathrm{~cm}^{2}$ determined by CT scan. The cut-off point of HDLcholesterol level was $40 \mathrm{mg} / \mathrm{dl}$ in both men and women, according to the criteria of the Japanese Atherosclerosis Society ${ }^{27}$ Using these criteria, $20.9 \%$ of men and $3.6 \%$ of women were diagnosed with the metabolic syndrome among a population of Japanese adults.

In the present study, men had significantly lower plasma adiponectin concentrations than BMI-adjusted women (median concentration of plasma adiponectin: $5.4 \mu \mathrm{g} / \mathrm{ml}$ vs $8.2 \mu \mathrm{g} / \mathrm{ml}$ ) as described in previous studies,$^{18}$ and the prevalence of hypoadiponectinemia was higher in men $(22.8 \%)$ than in women $(8.8 \%)$. The incidence of CAD is lower in women than in men and a higher plasma concentration of the anti-atherogenic protein, adiponectin, may be one of the reasons for the lower risk of CAD in women. It is not appropriate to set a more rigid cut-off value for the simple reason of a higher distribution of plasma adiponectin con- 
centrations in women. Subjects with hypoadiponectinemia less than $4.0 \mu \mathrm{g} / \mathrm{ml}$ had almost the same number of risk factors whether male $(2.57 \pm 1.34)$ or female $(2.00 \pm 1.51)$; $52.3 \%$ of men and $37.5 \%$ of women in this category fulfilled the criteria of the metabolic syndrome. Previously, we reported that subjects with plasma adiponectin concentration less than $4.0 \mu \mathrm{g} / \mathrm{ml}$ had a 2 -fold increase in the incidence of $\mathrm{CAD}_{2}^{28}$ and taken together with the present results, we propose setting a plasma adiponectin concentration of less than $4.0 \mathrm{\mu} \mathrm{g} / \mathrm{ml}$ as the cut-off point for hypoadiponectinemia. However, the number of female subjects diagnosed with the metabolic syndrome in this study was still small and the association of hypoadiponectinemia with the prevalence of CAD in women has not been investigated. Further large-scale surveys are necessary to evaluate the significance of plasma adiponectin in the prevalence of metabolic syndrome in women.

Plasma adiponectin concentrations as an inverse predictor of cardiovascular outcomes has been demonstrated in patients with end-stage renal disease ${ }^{31}$ The relative risk of adverse cardiovascular events was 1.56-fold higher among patients in the lower adiponectin tertile than in those in the higher tertile. Recently, a case-control study of 18,255 participants in the US showed higher plasma adiponectin concentrations were associated with lower risk of myocardial infarction independently of other risk factors in men 32 Clinical evidence demonstrating that correction of reduced plasma adiponectin can reduce the risk of CAD needs to be accumulated.

The metabolic syndrome is not simply a pathogenic clustering of multiple risk factors by chance. Obesity is frequently accompanied with hypertension, glucose intolerance, and dyslipidemia, but the prevalence of obesity greater than BMI 30 is only $2-3 \%$ in eastern Asia and it has been reported that BMI is not associated with CAD in Asians $3^{33}$ Establishment of criteria appropriate for eastern Asian populations is needed. Accumulation of fat in the intra-abdominal cavity is associated with hypertension, glucose intolerance, dyslipidemia, and CAD also in the Japanese population and accumulation of visceral fat, even in the non-obese, may play a central role in the metabolic syndrome ${ }^{34}$ In the management of the metabolic syndrome, appropriate biomarkers are needed and inflammatory markers, including C-reactive protein, are candidates in Japanese also 35,36 Adiponectin will be a novel biomarker for the metabolic syndrome.

Weight reduction increases the plasma adiponectin concentration; $21 \%$ reduction in BMI resulted in a $46 \%$ increase of plasma adiponectin concentration in obese subjects ${ }^{37}$ Therapeutic agents (ie, adiponectin promoters) can elevate the plasma adiponectin concentration. In mice and humans adiponectin promoters have a nonclassical peroxisome proliferator responsive element, which activates receptor gamma ligands, thiazolidinediones, promoting adiponectin activity and raise its plasma concentration? 38 It has also been reported, still controversially, that blockade of the renin-angiotensin system ${ }^{39}$ and the sulfonylurea reagent, glimepiride, ${ }^{40}$ increase the plasma adiponectin concentration, but whether these reagents can reduce the incidence of CAD in subjects with the metabolic syndrome, and whether the increase of plasma adiponectin induced by these reagents participates in the reduction of CAD, needs to be clarified in large-scale clinical trials.

In countries exposed to overnutrition, hypoadiponectinemia may become a secondary target for the prevention of atherosclerotic vascular diseases beyond hypercholesterolemia, and the measurement of plasma adiponectin may be useful for management of the metabolic syndrome.

\section{Acknowledgments}

We are grateful to Dr Kazuaki Kotani (Osaka Health Club Clinic), Dr Minoru Miyanaga (Senri Life Science Center Clinic), and Dr Katsuto Tokunaga (Itami Municipal Hospital) for their help in undertaking the health examination of the subjects participating in the Japanese Visceral Fat Syndrome (J-VFS) Study Committee of the Ministry of Health and Welfare of Japan.

\section{References}

1. Sniderman AD, Furberg CD, Keech A, Roeters van Lennep JE, Frohlich J, Jungner I, et al. Apolipoproteins versus lipids as indices of coronary risk and as targets for statin treatment. Lancet 2003; 361: $777-780$.

2. Grundy SM. Hypertriglyceridemia, insulin resistance, and the metabolic syndrome. Am J Cardiol 1999; 83: 25F-29F.

3. Kahn BB, Flier JS. Obesity and insulin resistance. J Clin Invest 2000; 106: $473-481$.

4. Kissebah AH, Vydelingum N, Murray R, Evans DJ, Hartz AJ, Kalkhoff RK, et al. Relation of body fat distribution to metabolic complications of obesity. J Clin Endocrinol Metab 1982; 54: $254-$ 260.

5. Fujioka S, Matsuzawa Y, Tokunaga K, Tarui S. Contribution of intra-abdominal fat accumulation to the impairment of glucose and lipid metabolism in human obesity. Metabolism 1987; 36: 54-59.

6. Nielsen S, Jensen MD. Obesity and cardiovascular disease: Is body structure a factor? Curr Opin Lipidol 1997; 8: 200-204.

7. Nakamura T, Tokunaga K, Shimomura I, Nishida M, Yoshida S, Kotani K, et al. Contribution of visceral fat accumulation to the development of coronary artery disease in non-obese men. Atherosclerosis 1994; 107: 239-246.

8. Matsuzawa Y, Nakamura T, Shimomura I, Kotani K. Visceral fat accumulation and cardiovascular disease. Obes Res 1995; 3(Suppl 5): $645 \mathrm{~S}-647 \mathrm{~S}$.

9. Friedman JM, Halaas JL. Leptin and the regulation of body weight in mammals. Nature 1998; 395: 763-770.

10. Hotmisligli GS, Arner P, Caro JF, Atkinson RL. Spiegelman BM. Increased adipose tissue expression of tumor necrosis factora in human obesity and insulin resistance. J Clin Invest 1995; 95: 24092415 .

11. Shimomura I, Funahashi T, Takahashi M, Maeda K, Kotani K, Nakamura T, et al. Enhanced expression of PAI-1 in visceral fat: Possible contributor to vascular disease in obesity. Nature Med 1996; 2: $800-803$.

12. Maeda K, Okubo K, Shimomura I, Funahashi T, Matsuzawa Y, Matsubara K. cDNA cloning and expression of a novel adipose specific collagen-like factor, apM1 (Adipose Most Abundant Gene Transcript 1). Biochem Biophys Res Commun 1996; 221: 286-289.

13. Ouchi N, Kihara S, Arita Y, Maeda K, Kuriyama H, Okamoto Y, et al. Novel modulator for endothelial adhesion molecules: Adipocytederived plasma protein adiponectin. Circulation 1999; 100: 2473 2476.

14. Ouchi N, Kihara S, Arita Y, Okamoto Y, Maeda K, Kuriyama H, et al. Adiponectin, an adipocyte-derived plasma protein, inhibits endothelial NF-kappaB signaling through a cAMP-dependent pathway. Circulation 2000; 102: 1296-1301.

15. Arita Y, Kihara S, Ouchi N, Maeda K, Kuriyama H, Okamoto Y, et al. Adipocyte-derived plasma protein adiponectin acts as a plateletderived growth factor-BB-binding protein and regulates growth factor-induced common postreceptor signal in vascular smooth muscle cell. Circulation 2002; 105: 2893-2898.

16. Ouchi N, Kihara S, Arita S, Nishida M, Matsuyama A, Okamoto Y, et al. Adipocyte-derived plasma protein, adiponectin, suppresses lipid accumulation and class A scavenger receptor expression in human monocyte-derived macrophages. Circulation 2001; 103: $1057-1063$

17. Okamoto Y, Arita Y, Nishida M, Muraguchi M, Ouchi N, Takahashi $\mathrm{M}$, et al. An adipocyte-derived plasma protein, adiponectin, adheres to injured vascular walls. Horm Metab Res 2000; 32: 47-50.

18. Arita Y, Kihara S, Ouchi N, Takahashi M, Maeda K, Miyagawa J, et al. Paradoxical decrease of an adipose-specific protein, adiponectin, in obesity. Biochem Biophys Res Comun 1999; 257: 79-83.

19. Hotta K, Funahashi T, Arita Y, Takahashi M, Matsuda M, Okamoto $\mathrm{Y}$, et al. Plasma concentration of a novel adipose-specific ptorein, 
adiponectin, in type 2 diabetetic patients. Arterioscler Thromb Vasc Med 2000; 20: 1595-1599.

20. Hotta K, Funahashi T, Bodkin NL, Ortmeyer HK, Arita Y, Hansen $\mathrm{BC}$, et al. Circulating concentrations of the adipocyte protein adiponectin are decreased in parallel with reduced insulin sensitivity during the progression to type 2 diabetes in rhesus monkeys. Diabetes 2001; 50: 1126-1133.

21. Lindsay RS, Funahashi T, Hanson RL, Matsuzawa Y, Tanaka S, Tataranni PA, et al. Adiponectin and development of type 2 diabetes in the Pima Indian population. Lancet 2002; 360: 57-58.

22. Ouchi N, Ohishi M, Kihara S, Funahashi T, Nakamura T, Nagaretani $\mathrm{H}$, et al. Association of hypoadiponectinemia with impaired vasoreactivity. Hypertension 2003; 42: 231-234.

23. Tokunaga K, Matsuzawa Y, Ishikawa K, Tarui S. A novel technique for the determination of body fat by computed tomography. Int $J$ Obes 1983; 7: 437-445.

24. Yoshizumi T, Nakamura T, Yamane M, Isram AHMW, Menju M, Yamasaki K, et al. Abdominal fat: Standardized technique for measurement at CT. Radiology 1999; 211: 283-286.

25. Expert Panel on Detection, Evaluation, and Treatment of High Blood Cholesterol in Adults. Executive Summary of the Third Report of the National Cholesterol Education Program (NCEP) Expert Panel on Detection, Evaluation, and Treatment of High Blood Cholesterol in Aduts (Adult Treatment Panel I). JAMA 2001; 285: 2486-2497.

26. The Examination Committeee of Criteria for Obesity Disease in Japan; Japan Society for the Study of Obesity. New criteria for 'obesity disease' in Japan. Circ J 2002; 66: 987-992.

27. Hata Y, Mabuchi H, Saito Y, Itakura H, Egusa G, Ito H, et al. Report of the Japan Atherosclerosis Society (JAS) guideline for diagnosis and treatment of hyperlipidemia in Japanese adults. $J$ Atheroscler Thromb 2002; 9: 1-27.

28. Kumada M, Kihara S, Sumitsuji S, Kawamoto T, Matsumoto S, Ouchi N, et al. Association of hypoadiponectinemia with coronary artery disease in men. Arterioscler Thromb Vasc Biol 2003; 23: 8589.

29. Isomaa B, Almgren P, Tuoml T, Forsen B, Lahti K, Nisses M, et al. Cardiovascular morbidity and mortality associated with the metabolic syndrome. Diabetes Care 2001; 24: 683-689.

30. Nakamura T, Tsubono Y, Kameda-Takemura K, Funahashi T, Yamashita S, Hisamichi S, et al. Group of the Research for the Association between Host Origin and Atherosclerotic Diseases under the
Preventive Measure for Work-related Diseases of the Japanese Labor Ministry. Magnitude of sustained multiple risk factors for ischemic heart disease in Japanese employees: A case-control study. Circ J 2001; 65: 11-17.

31. Zoccali C, Mallamaci F, Tripepi G, Benedetto FA, Cuturupi S, Parlongo S, et al. Adiponectin, metabolic risk factors, and cardiovascular events among patients with end-stage renal disease. J Am Soc Nephrol 2002; 13: 134-141.

32. Pischon T, Girman CJ, Hotamisligli GS, Rifai N, Hu FB, Rimm EB. Plasma adiponectin levels and risk of myocardial infarction in men. JAMA 2004; 291: 1730-1737.

33. Tseng $\mathrm{CH}$. Body composition as a risk factor for coronary artery disease in Chinese type 2 diabetic patients in Taiwan. Circ J 2003; 26: $479-484$.

34. Kobayashi H, Nakamura T, Miyaoka K, Nishida M, Funahashi T, Yamashita S, at al. Visceral fat accumulation contributes to insulin resistance, small-sized low-density lipoprotein, and progression of coronary artery disease in middle-aged non-obese Japanese men. Circ J 2001; 65: 193-199.

35. Saijo Y, Kiyota N, Kawasaki Y, Miyazaki Y, Kashimura J, Fukuda $\mathrm{M}$, et al. Relationship between $\mathrm{C}$-reactive protein and visceral adipose tissue in healthy Japanese subjects. Diabetes Obes Metab 2004; 6: 249-258.

36. Saito I, Yonemasu K, Inami F. Association of body mass index, body fat, and weight gain with inflammation markers among rural residents in Japan. Circ J 2003; 67: 323-329.

37. Yang WS, Lee WJ, Funahashi T, Tanaka S, Matsuzawa Y, Chao CL, et al. Weight reduction increases plasma levels of an adipose-derived anti-inflammatory protein, adiponectin. J Clin Endocrinol Metab 2001; 86: 3815-3819.

38. Maeda N, Takahashi M, Funahashi T, Kihara S, Nishizawa H, Hishida K, et al. PPARy ligands increased expression and plasma concentration of adiponectin, an adipose-derived protein. Diabetes 2001; 50: 2094-2099.

39. Furuhashi M, Ura N, Higashiura K, Murakami H, Tanaka M, Moniwa N, et al. Blockade of the renin-angiotensin system increases adiponectin concentrations in patients with essential hypertension. Hypertension 2003; 42: 76-81.

40. Nagasaka S, Taniguchi A, Aiso Y, Yatagai T, Nakamura T, Nakai Y, et al. Effect of glimepiride on serum adiponectin level in subjects with type 2 diabetes. Diabetes Care 2003; 26: 2215-2216. 